\title{
A Psychoanalytical Reading of The Game of Forgetfulness
}

\author{
Gholamreza Karimi Fard \\ gh.karimifard@scu.ac.ir
}

Associate Professor of Arabic Language and Literature of Shahid Chamran University of Ahvaz, Ahvaz, Iran |(Corresponding Author).

Parvin Khalili

parvinkhalili93@gmail.com

$\mathrm{PhD}$ student in Arabic Language and Literature of Shahid Chamran University of Ahvaz, Ahvaz, Iran.

\author{
Masoud Bavanpouri \\ masoudbavanpouri@yahoo.com \\ $\mathrm{PhD}$ in Arabic Language and Literature, Azarbaijan Shahid Madani University, \\ Tabriz, Iran.
}

\begin{abstract}
Within the pasr few decades, psychological criticism has become an integral part of literary criticism, paving the way for a proper understanding literary texts. The analysis of authors' emotional and psychological condition is of prime significance in this regard. Sigmund Freud, the founder of modern psychology, postulated three levels of human awareness: the preconscious, the conscious, and the unconscious which are tinged with sexual and aggressive impulsesThe psychological make up is composed of the ego, the id, and the super ego which constitute the core of an individual's personality. The Game of Forgetfulness (1987) is one of the most important novels written by Muhammad Barada and has been subject to numerous studies by scholars from various fields. This paper studies the presentation of grief and psychological conflict in characters' social relations. The main theme in the novel concerns the psychological condition of some family members after the death of their mother, and the problems and difficulties they meet in the society. A psychological analysis sheds light on their preocupation with depression, grief, psychological conflict, and nostalgia which are symptomatic of Barada's society. The characters suffer from obsessions, ailments, and anguish caused by disasters and mischeifs.
\end{abstract}

Keywords: Psychological criticism, Freud, game of forgetfulness, Muhammad Barada, Arabic Narratology

Citation:Karimifard, Gholamreza; Khalili, Parvin; Bavanpouri, Masoud. Spring and Summer (2021). A Study of Muhammad Barada's novel The Game of Forgetfulness, in the Light of Sigmund Freud's Psychoanalytical theoryStudies in Arabic Narratology, 2(4), 111-139. (In Arabic) 
Studies in Arabic Narratology, Spring and Summer (2021), Vol. 2, No.4, pp. 111-139

Received: May 22, 2021 Accepted:October 17, 2021

CFaculty of Literature \& Humanities, University of Kharazmi and Iranian Association of Arabic Language \& Literature. 


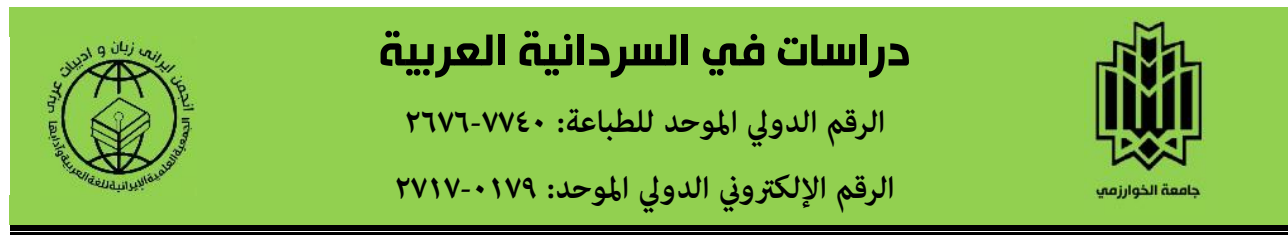

\section{دراسة رواية "لعبة النسيان" لمحمد برادة في ضوء نظرية سيغموند فرويد}

\section{النفسية}

gh.karimifard@scu.ac.ir

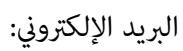

غلامرضا كريمي فرد

أستاذ مشارك في قسم اللغة العربية وآدابها بجامعة شهيد جمران أهواز، أهواز، إيران.(الكاتب المسؤول) parvinkhalili93@gmail.com

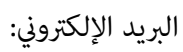

بروين خليلي

طالبة الدكتوراه في قسم اللغة العربية وآدابها بجامعة شهيد جمران أهواز، أهواز، إيران

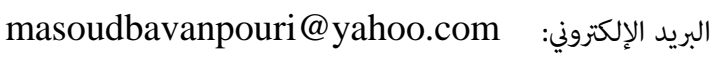
مسعود باوان بوري دكتوراه في قسم اللغة العربية وآدابها بجامعة الشهيد مدني بأذربيجان.

الإحالة: كريميفرد، غلامرضا وخليلي، بروين وباوان بور، مسعود. ربيع وصيف (اب.r(). دراسة رواية "لعبة النسيان" لمحمد برادة في ضوء نظرية سيغموند فرويد النفسية، دراسات في

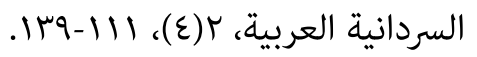

دراسات في السردانية العربية، الربيع والصيف (اب.r()، السنةr، العددع، صص.

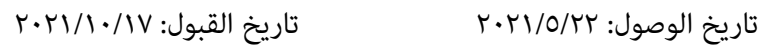

ه كلية الآداب والعلوم الإنسانية بجامعة الخوارزمي والجمعية العلمية الإيرانية للغة العربية وآدابها.

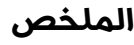

اليوم أصبح النقد النفسي جزءا لا يتجزأ من الأدب. ولفهم النص الأدبي بشكل صحيح، يقتضي بالضرورة، الحديث عن الحالات النفسية والوجدانية للكاتب ويتم تحديده في سياق كلمات وسلوك شخصيات الرواية لذلك، لفحص عقلية الكاتب وحالاته النفسية والروحية، يجب علينا أن نفحص كيف يتم التعبير عن أفعال وكلام الشخصيات خلال الرواية. من أشهر علماء النفس "سيغموند فرويد" الذي يؤمن 
بوجود ثلاثة أقسام للجهاز النّفسي؛ هي الشّعور وما قبل الشعور واللاشعور. والقسم الثالث يحتوي على الدوافع الغريزية البدائية الجنسية والعدوانية؛ أي أنّ الحياة

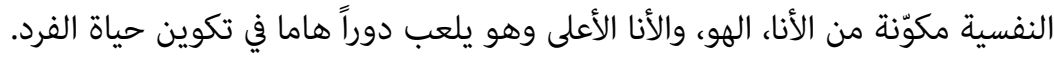

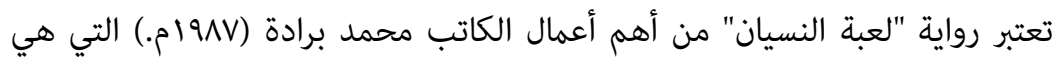
موضع دراستنا في ضوء النقد النفسي حسب نظرية فرويد- ومتمسكا بالمنهج الوصفي

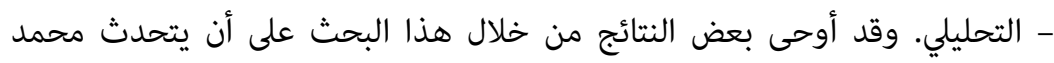
برادة في روايته عن الأم والصراع النفسي بين الناس والمجتمع. الموضوع الرئيس للرواية هو حالة بعض أفراد الأسرة النفسية بعد وفاة والدتهم والمشاكل والمصاعب التي يواجهونها في مجتمعهم. ونرى من خلال التحليل النفسي أنهّم يعانون من الكآبة

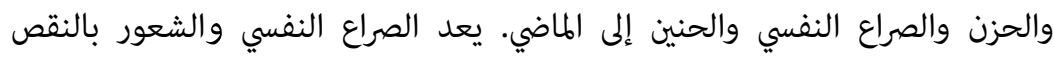

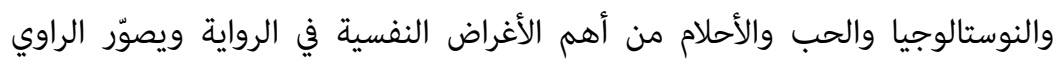
حياة شخصيات مجتمعه من خلال هذه الأغراض. توجد داخل الشخصيات العقد والأمراض والآلام بسبب مصائب الحياة أو نتيجة ندم على خطاء مينداء يرتبكونهم.

الكلمات الدليلية: الرواية، النقد النفسي، فرويد، لعبة النسيان،محمد برادة,

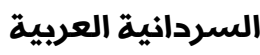

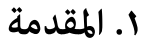

للتّحليل النفسي معانٍ متعددة، فمنها تعريف فرويد الذي ذكره فيصل عباس، حيث يقول: " (ركان فرويد يؤكد على أنّ التّحليل النّفسي له ثلاثة معانٍ مختلفة: اـ طريقة العلاج تستخدم

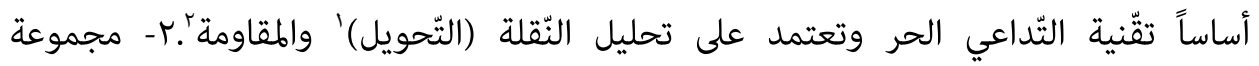
النّظريات في الوظائف السيكولوجية للفرد تؤكد على دور وأهمية اللّاوعي والقوى الدّينامية في

1 - Transfer

2 - Résistance 
الوظائف النّفسّية.ب- طريقة للبحث في وظائف وعمل النّفس السّوية واللّاسّوية؛ أي ما يحدث

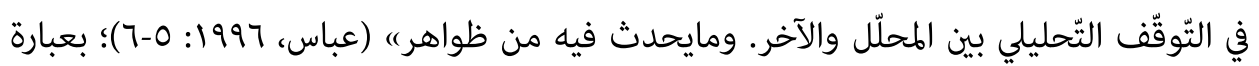
أخرى، خلق فرويد معنى يقدم فيه العلاج والتعبيرات على أساس مجموعة من المبادئ والنظريات التي تثبت أهمية العقل الباطن للفرد، وكذلك النهج الذي يفحص عمل الروح.

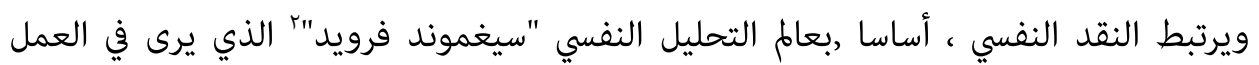
الأدبي موقعاً أثريا ذا طبقات من الدلالات متراكمة بعضها فوق بعض، ولابدّ من الغور فيها للكشف عن غوامضه وأسراره. فيرى فرويد أنّ الأدب والفنون العامة تعتبر تعبيرات عن هذه منه منه الرغبات المكبوتة لأنّ الأدب، باعتباره عنصرا من العناصر الثقافيّة الهامّة، يعبّر عن حقائق المجتمع والفرد والبيئة. استطاع فرويد أن يرسخ مفهوما للأدب ويحجز له مكانة في الساحة النقدية حيث يقول عنه

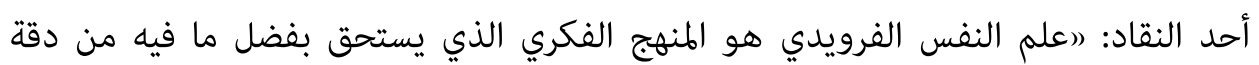
وعمق وتركيب، وبفضل ما ينطوي عليه من فائدة وقوة مأساوية، أن يقف وحدة مقابل ذلك الركام المضطرب من النظريات السيكولوجية التي تجمعت في الأدب خلال القرون) (تريلنج، . (E) : I $9 \vee 0$ ويعدّ التّحليل النفسي منهجاً خاصا عند العرب، ويمكن تطبيقه على الأدب؛ (فإذاذا ما نظرنا إلى تاريخ الفهم النّفسي للأدب عند العرب وجدنا ملاحظات المبدع وظروفه النّفسية) (الرّديني

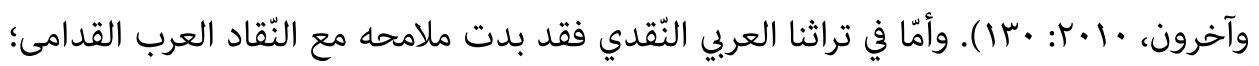
فيعدّ ابن قتيبة من أوائل من تلمّس البواعث النّفسيّة في الشّعر بين النّقاد، فنراه يطرح العوامل النّفسية التي تحتفي وراء العمل الأدبي والمنحصرة في إطار الباعث الشّعوري كالغضب والطّرب والشّوق والحالات الأخرى ليس الشرابُ، ومنها الطربُ، ومنها الغضب" أكثر يقول: "روللشعر دواعٍ

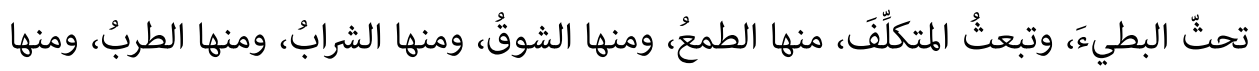
الغضبُ)، (ابن قتيبة، د.ت: V^).

1 - Psych

2- Sigimund Freud 
نضج النّقد النّفسي لدى العرب مع نقد جماعة الدّيوان، ومن تبعها من الأدباء والنّقاد

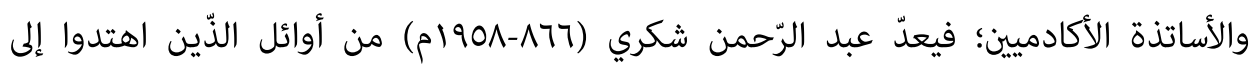
الإفادة من حقائق علم النّفس في دراسته للشّعر، فقد كان شكري "أمام الجماعة في مرحلتها الأولى لا يبعد أن يكون لتوجيهاته الشفوية دور في توجيه زميليه نحو الاستفادة من معطيات علم النّفس، وكان أصحابه يستمتعون كثيرا بأحاديثه ... وهو ما يبدو من كلام العقّاد أوّل مَن مَن حاول تطبيق المعارف النّفسيّة على ما يقرأه من شعر الفحول في اللغة العربية)، (مجموعة من

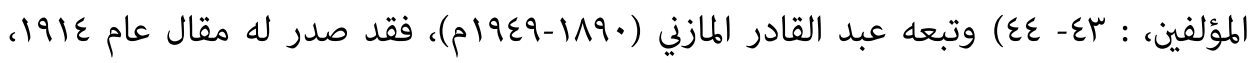
درس فيه شعر ابن الرّومي في ضوء علم النّفس (عكاشة، 1910: IIV) ثم جاءت دراسة عبّاس محمود العقّاد (9M9-197/م)، في دراسة مماثلة للشّاعر نفسه، ولأبي نواس وغيرهما. كما تناول محمد النويهي بدراسة نفسية الشّاعرين السّابقين. ولد محمد برادة (^بوام.)، الروائي والناقد المغربي، في "الرباط". ويكتب القصة والرواية، كما يكتب المقالة الأدبية والبحث النقدي، وله في هذه المجالات جميعها العديد من الدراسات وبعض الكتب ذات الأثر اللافت في المشهد الثقافي والأدبي والنقدي العربي، ككتابه الهام حول محمد مندور وكتابه النقدي حول الرواية العربية. من أشهر رواياته رواية "لعبة النسيان" التي تعد من أبرز النصوص الروائية المغربية التي تنحو منحى التخييّل في معالجة قضايا المجتمع المغربي منذ عهد الحماية إلى أواخر العقد الثامن من القرن الهاضي. تبدد الرواية الصور النمطية الكلاسيكية التي طغت على الرواية المغربية لعقود، سواء على مستوى المضمون من سير لأغوار الذات الإنسانية في سلوكاتها الشعورية واللاشعورية وما تتطرق إليه من تيمات جريئة كالجنس والسلطة والاستبداد، أو على مستوى علم النفس كالأحلام وتيار الوعي والتداعي الحر داخل الشخصيات والصراع النفسي و غيرها من مواضيع · في الواقع يدرس علم النفس في علاقته بالأدب، مراحل التطور البشري وشخصية الإنسان ـ وخلال هذه الدراسة , يبحث عن تقدمه أو ركوده في إقامة أو عدم إقامة العلاقة مع البيئة والأسرة. ويستكشف مراحل نهوه الكاملة من الطفولة إلى منتصف العمر والشيخوخة من وجهات نظر مختلفة. 


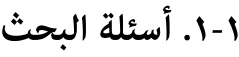

عالجنا في هذا البحث التحليل النفسي عند فرويد، ودرسنا رواية "لعبة النسيان" لمحمد برادة

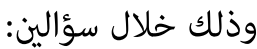

ا - كيف تجلى التحليل النفسي في رواية لعبة النسيان؟ r- ما هي رؤية شخصيات الرواية للعالم من حولهم؟

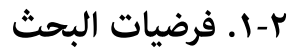
ا. يبدو بالنظر أنّ الصراع النفسي، الشعور بالنقص، تيار الوعي والتداعي الحر، النوستالوجيا، الحب والأحلام من أهم الأغراض النفسية التي نشاهدها في الرواية. r. وأيضا نشاهد داخل الشخصيات، العقد والأمراض والآلام بسبب مصائب الحياة أو نتيجه ندم على أخطاء يرتبكونهم. كما يمتاز البعد النفسي في هذه الرواية بالتوتر والقلق والإضطراب الذي يبدو قاسماً مشتركاً لدى كل الشخصيات رغم اختلاف الأسباب . وهذا يسبب داخل داخل الشخصيات الشعور بعدم بالطهأنينة.

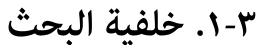

تم إجراء الكثير من الأبحاث في عالم الرواية على أساس المنهج النفسي والتي لا نذكرها هنا. وخلال البحث حول الدراسة النفسية لرواية "لعبة النسيان"لمنعثر على بحث خاص، ولكن تبين أنه تم اجراء بعض الدراسات في ضوء البنية السردية والعتبات النصية حول الرواية، منها: "العتبات النصية في روايات محمد برادة "لعبة النسيان" و"امرأة النسيان" أفوذجاه، (19 •بم)؛ من حنان دغوم ورجاء بن عمر، الجزائر: جامعة الوادي. برز في هذه الرواية لنا بأن شكلت وحدات أيقونية محشوة ومفعمة بمجموعة من الدلالات والإيحاءات التي تسمح بولوج البنية الكبرى للنص المثنى واقتحام أغواره وفهم مكوناته. (البنية السردية في الرواية المغاربية - رواية " لعبة النسيان" لمحمد برادة أفوذجاه، (10 آبم)؛ من سيدة فاطمة الزهراء طرابلسي وعزالدين عماري، رسالة الماستر في الأدب العربي الحديث، جامعة محمد بو ضيفات بالمسيلة؛ تدرس هذه الرسالة تجليات التعدد الصوتي (البوليفينية) في هذه الرواية من خلال البنية والدلالة والوظيفة 
الخاصة بتعدد الاصوات. لذلك، بعد التعرف الإجمالي على نظرية فرويد النفسية، ندرس مفاهيم هذه النظرية كما ظهرت في رواية لعبة النسيان.

\section{ع-ا. أسس نظرية فرويد النفسية}

التحليل النفسي لفرويد هو في الأساس، علاج سريري للمرضى الذين يعانون من أمراض عصبية، و-هي أيضا الطريقة التي تنظر بها إلى أعماق اللاوعي التي نرفض التعرف عليها بشكل واعي؛ بعبارة أخرى يحاول التحليل النفسي تقييم وتحليل هذه المنطقة من العقل البشري والتدقيق فيها، كما أنه يكشف عن الأسرار التي نخاف الإفصاح عنها. فيقول جون بلمان نويل' (1M01 - سا971م): (التحليل النفسي، أقصد به المذهب الفرويدي، لا العلم، هو فن تفكيك رموز الحقيقة في القطاعات الغامضة للتجربة الإنسانية كما يعيشها الإنسان، أي كما يرويها للآخرين

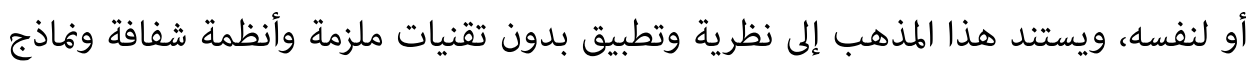
طبق الأصل ومفاهيم أحادية المعنى، ونقاط استدلال ثابتة) (لابلانش، r. .r: 170). في هذا السياق، أكدّ فرويد على أن الفرد محكوم عليه من قبل القوى اللاواعية التي تسير به وتحدد مسار حياته وبهذا أنزل ضربة قاضية على المدرسة الشعورية. وفقا لفرويد، فإن هذا الجزء من العقل السطحي ليس سوى جزء صغير من الشخصية البشرية، وقد شبه فرويد الحياة النفسية بجبل من الجليد يمثل اللاشعور الجزء الأكبر الموجود في الأعماق، ولهذا تسمي مدرسة التحليل النفسي أحيانا سيكولوجية الأعماق، وفي هذه المنطقة من اللاشعور توجد الدوافع الأولي والرغبات والمشاعر المكبوتة. وهكذا انتهى فرويد إلى القول بأن الاقتصار على الشعور غير كاف

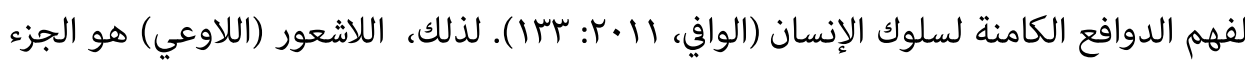
الرئيس في رأي فرويد، إذ يفترض دائا أنه عبارة من المنطقة الشاسعة من الحياة النفسية التي تشتمل على الرغبات المكظومة والذكريات والمشاعر التي قد ترجع إلى السنوات الأولى من حياة الفرد. كذلك، فإن اللاشعور هو "ذلك الجزء من النفس الذي يصل إلى درجة الإبهام والغموض،

\footnotetext{
${ }^{1}$ - John palmant noei (1885- 1963)
} 
بحيث لانعرف عنه إلا مظاهره، والذي يعتبر مصدراً للنشاط العقلي الذي يستمر حدوثه بدون

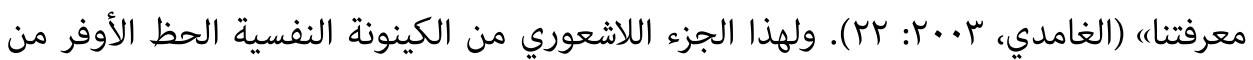

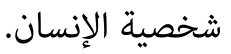
لقد قام فرويد بتعديل الدوافع والرغبات المكبوتة من اللاشعور، وأطلق على هذا المستودع من الرغبات اسم الهو، الذي يشمل كل ما هو موروث وما هو موجود، ولايعترف بالمنطق أو هرت الأخلاق أو الواقع. واللاشعور هو الكيفية الوحيدة التي تسود فيه، بيد أنه من اللازم أيضا أن

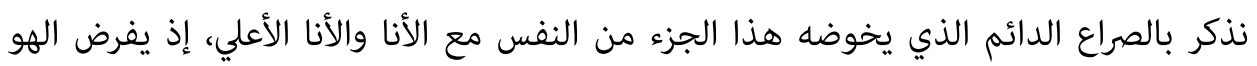
نزواته اللاواعية وذكرياته التي ترسبت فيه على مدى السنين على الأنا الذي يقاوم دائما ويحاول المحافظة على التوازن، هذا التوازن الذي يفقده أثناء الاستسلام للأحلام، بينما يشكل الأنا الأعلى تركي تلك المنظمة العليا التي تسهر على تقنين كل هفوة من نفس الإنسان، ويبدأ بالتشكل منذ إدراك

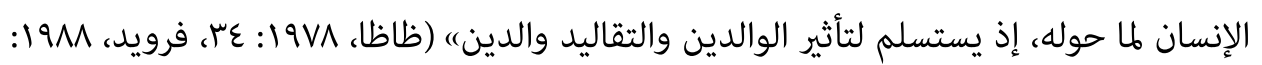
IV IV. لذلك، يستطيع الباحث من خلال هذا الاتجاه الكشف عن انفعالات وتحولات الشخصية الروائية من خلال التحليل النفسي لفرويد لتلك الشخصيات وشرحها ودراستها ذهنياً للوصول إلي هني معرفة الغايات والاهداف التي تكمن وراء أحداث الرواية وما يبرز من رموزها لكي نصل إلي الأفكار الكامنة في ذهن الراوي.

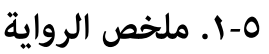

تعد رواية "لعبة النسيان" من بين أهم مؤلفات الروائي المغربي محمد برادة وفي قائة أفضل

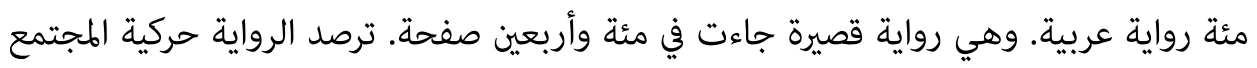
المغربي في أواخر فترة الاستعمار وبداية الاستقلال وما تلاه، مثلما-تكشف التفاوت الاجتماعي الصارخ بين المغاربة والمستعمرين من جهة وبين فئات المجتمع المغربي من جهة ثانية من خلال رصد ثلاثة أجيال داخل العائلة الواحدة، إذ تدور وقائع الرواية حول حياة عائلة لالة الغالية (مع أبنائها؛ الهادي والطايع، وابنتها لالة نجية، وزوج ابنتها سي إبراهيم وأخيها سيدالطيب، وزوجة إنها

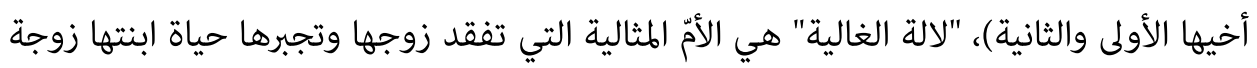
إبراهيم على الانتقال من "فاس" إلى "الرباط" بغية الاعتناء بأبنائها. غير أن الهادي الإبن الصغير 
يقرر العودة إلى فاس حيث مهد ذكريات الطفولة الجميلة بعد وفاة والدته. موضوع الرواية الأساسي هو فقدان إنسان عزيز وغال، وهي "الأم"، التي تحتل فيه مكانة كبيرة. (الرواية تركز على لحظتين مركزيتين في حياة "الهادي"، الشخصية المحورية في الرواية: الأولى لحظة موت الأمّ: لالة الغالية، تلك المرأة التي لا تعوّض ولا توصف، والثانية لحظة موت امرأة أخرى هي أول موضوع للحب والشهوة والرغبة المشتعلة: هي "لالة ربيعة" زوجة خاله. مناخ الرواية النفسي يخيّم عليه التوجّع والتفجّع والضيق والكآبة. ويمارس الراوي لعبة النسيان، نسيان الآلام والأوجاع، ويدعو إلى استحضار الذكريات والشروع في تشخيص متخيّل للشيء العزيز المفقود والمفتقد.

\section{ا. انعكاس نظرية فرويد في الرواية}

"النقد النفسي في الأدب يعني محاولة اكتشاف القضايا النفسية من خلال النصوص الأدبية وهو نوع من التعبير عن العلاقة بين الأساليب السريرية والعلاجية في علم النفس) (مجيدي وآخرون، عوبا: •ع(1)، لذلك نوضّح مفاهيم هذه النظرية ونبحث عنها في رواية لعبة النسيان.

\section{ا-r-r. الصراع النفسي}

الصراع النفسي هو من أنواع الصراع الذي ينشب داخل المرء نفسه، و يوصف بأنه (اتعارض الفرد بين القوتين إحداهما دافعة وأخرى مانعة، وكثير مايجد الإنسان نفسه أنه لايستطيع أن

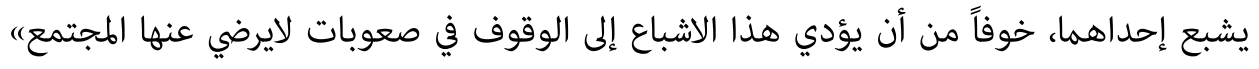

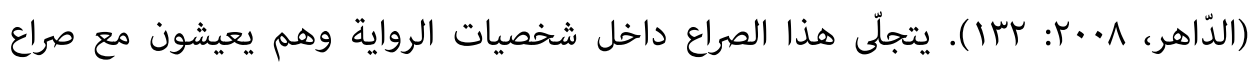
داخلي بين العواطف والمشاعر-المتناقضة التي دفعتهم أحيانا إلى القيام بردود أفعال متباينة تصل إلى حد الغرابة. في بعض الأحيان، يتم قمع العادات الاجتماعية والظلم من خلال آليات الصراعات النفسية داخل الشخصيات. وحسب نظرية فرويد، كما قلنا سابقا، بأن الحياة النفسية عند الإنسان، مكوّنة من الأنا، والهو والأنا الأعلي وتساهم في تكوين حياة الفرد النفسية، هذه القوى مختلفة دائما وهذا الاختلاف هو سبب نضالات المرء النفسية؛ حيث يقول فرويد: (أنّ هذه القوي في حالة صراع دائم، وقد يتغلب بعضها علي بعض عن طريق القمع، أو الكبت، أو التّسامي، أو التّبريد، أو 
القلب، أو القهر حسب مصطلحات فرويد نفسه، وفي حالات أخري يصل الصرّاع إلي قمة بين

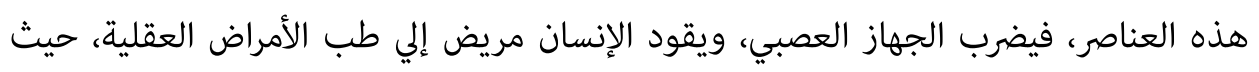
يضطلع التّحليل النّفسي بعلاجه) (ذهني، د.ت: هTV)؛ وهذا يعني أن الصراع بين هذه القوى يؤدي إلى المرض العقلي والصراع النفسي لدى الفرد.

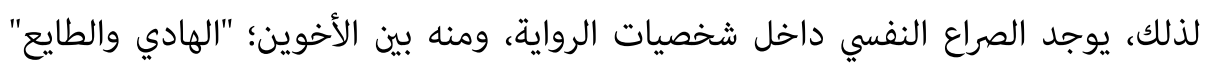
لأن آراءهما ونظراتهما في الحياة وفلسفتها وحالاتهما النفسية مختلفتان، كما أنهما ينتقدان كل منهما آراء الآخر ويرفضان فكرته. وجاء هذا الاختلاف في كلام الطايع هكذا: (اعلاقتي بالهادي أيضا اتخذت طابعا حادّا، عدوانيا، يتعدي نطاق التنافس الذي كان بيننا. أحار من تحديد شعوري نحوه، لأن حبي له كان بدون حدود منذ طفولة، وازداد عندما سلك سبيله إلى الجامعة بمساعدتي، لكننا اختلفنا في التفكير وفم العيش. أصبح نقيضي: دائما يفترض اشراكا منصوبة أمامنا، وعلينا أن نتجنبّنا لكي لايغرّر بنا، لابد من تحليل كل شئ، يقول والطبادئ على أهميتها،

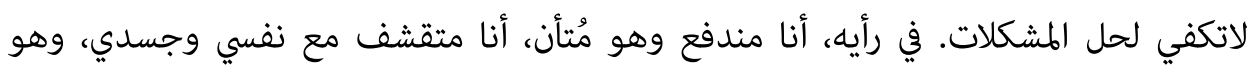
مفتون بالجسد واللذة. أصفه بالأناني فيقول: فعلا، لايكن أن نعيش بدون أنانية. أحثّه على مهنى

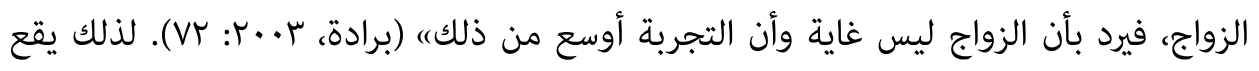
الطايع في الصراع النفسي والهذيان والأنانية؛ كما يقول فرويد: (الأنا منذئذ تحت سيطرة الهو،

$$
\text { وسيطرة الدوافع الباطنية)، (فرويد، عـ9 1: 9). }
$$

لذلك، قام فرويد من وجهة اللاشعورية بالتّحليل النّفسي. إنه حديث الشخصيات، بعد الفاصل بينها وبين الواقع، يكسرها إلى ما بعد مرحلة الوعي، وهذا بسبب الضغوط النفسية الشديدة. هذه الكلمة ينطق بها شخص لديه مراع بين نفسه وبين واقع بيئته، مما جعله ينتقل من مرحلة الوعي إلى اللاوعي. ترك هذه المرحلة والدخول في اللاوعي تسبب في الكثير من الضغط عليه، فتتحرر عن عالم الواقع ويبقي في عامل الهذيان؛ كما التحليل النفسي يحوي الدوافع الغريزية البدائية الجنسية والعدوانية التي غالبا ما تكبت في مجتمعاتنا المتحضرة تحت تأثير المعايير الاخلاقية والدينية والإجتماعية التي ينشأ فيها الفرد.كمارتعتبر العوامل الوراثية والبيئية (الاجتماعية والثقافية) فعالة للغاية في تقوية وإضعاف السمات الشخصية لبعض أقطاب شخصية الإنسان، وهذه العوامل تجعل الشخصية البشرية مختلفة عن بعضها البعضه (خزلي 
وآخرون، سوسا: 70)؛ وهكذا، فالطايع يعيش في الصراع النفسي في تفسيره عن الهادي وأفكاره حوله، الصراع النفسي أوقعهم في التناقض. اندهش الطايع من ما حدث بين حبه لأخيه الهادي وكرهه له، لأنه في وسط شيئين متناقضين. هو يشرح هذا الصراع النفسي بسبب تعريض الهادي له، ويقول: (مشاهد قلما أسترجعها أو أدَغدغها بيني وبين نفسيني، يقول هي لي الهادي في صيغة متفلسفة وهو يقصد التعريض بي: "أظن أن الكثيرين يشقون لأنهم عاجزون عن استرجاع طفولتهم وإدماجها في حياتهم الراهنة ..." هل يعقل أن أستأصل طفولتي، طفولتنا من الذاكرة؟ إنه يلتذّ بأن يصوغ عبارات يلخص بها حالات الآخرين. أستمع اليه وأبتسم. ومع الأيام أحسني أغوص تدريجياً في سديم العلائق المكرورة والمواضعات الاجتماعية. والآن لااستطيع أن أحلل شيئاً يتصل بجسدي وحياتي الزوجية)، (برادة، ب. •ץ: 79). لقد ألقى الصراع والهذيان ظلاله على له الطايع وجعله يحكي عن آلامه النفسية وتصعد إلى قمة الجنون والإغتراب وشعر بتلك اللحظة الموجعة التي لقى الهادي ويتكلم معه وما جعله بحديث فاقد لمنطقية الفهم. يبحث الطايع عن ملجأ لتنفيذ الرغبات الكامنة في لا وعيه، فأختار الهذيان ليفجر طاقات البوح والاعتراف لأخيه الهادي بسبب صراعه النفسي. ويقع الهادي في التناقض بين نفسه وأخيه الطايع وأيضا بين نفسه وأخته، ومن فاذج الصراع النفسي داخله مع أخته، حين يري المقارنة بينه وبين أخته في حبه لأخته الأخري "لالة نجية"، ولكن هو لايسمع كلاما جميلا من أخته، لذلك يقع في الصراع النفسي ويقول هكذا: (أحسستُ أن تصريحي أخطأ الهدف. حاولت أن أتدارك فقلتُ لها بأن نوع الحياة الذي أعيشه يجعلني دائما أجري وراء سراب. مهملاً الحقائق التي تعيش على مقربة مني... غمرني شعور غبطة وحنان

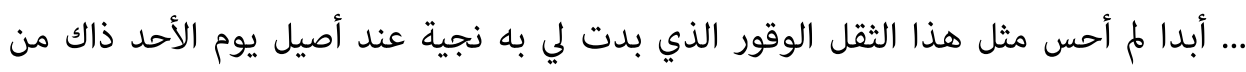
خلال حديثها ونظراتها. كانت تردد أنها سعيدة لأنها تحمل في قلبها قناعة الآخرة، لكنني عندما

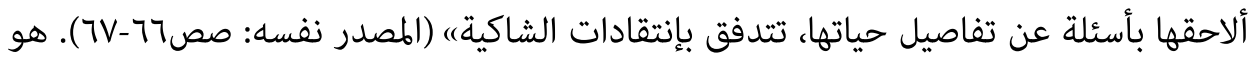
داخله مملوء بالأسئلة حول أخته هاذا أختي تجبني هكذا؟ ماذا صار هكذا؟ ماذا؟... هو لا يجد ردا لأسئلته ويقع في الصراع النفسي والهذيان في نفسه. هذا الأمر جعله يهذي ويهلوس ويمر بصدمات نفسية بشكل التوتر والانفعال لتتفجر مشاعره الهائمة بداخله إلى هذيان حاد. والصراع النفسي لشخصيات، يجعل القارئ يدرك تماما حالة التأزم التي وصل اليها. 


\section{r-r. النوستالوجيا}

"أفي بداية القرن العشرين، تحول مصطلح النوستالوجيا إلى كونه اضطرابا نفسيا، وقد شملت أعراضه القلق والحزن والضعف، والعرق والحمى، وأُعتبر الحنين حينها شكلاً من أشكال القال

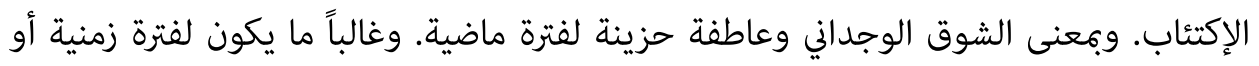
مكان، ارتبطت في ذاكرة الإنسان بعلاقات الشخصية السيئة التي كانت تواجه بها في الماضي،

$$
\text { (عبدالكريم قاسم وآخرون، د.ت: ع^ع). }
$$

العاطفة هي أيضا من صفات النوستالجيا، فهي إيجابية محملة ببعض مشاعر الحزن والأسى الحرى

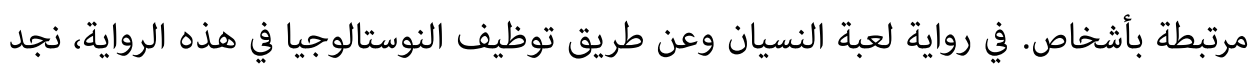
تأثيرها على وجدان الشخصيات، وبالاعتماد على الصورة أو المشهد العاطفي الماضي، توجد الآلام والأحزان داخل الشخصيات بسبب فقدان الماضي وما فيها. منهم "الهادي" من الشخصيات المحورية في الرواية عندما يتذكر الأيام الماضية التي قضى عند أمّه وكان في عيش وترف. فئه ويتحدث إلى والدته في شكل حوار داخلي: (أذكر الطفولة وأذكر الشباب، فأذكر المراهقة فأذكر مَصَّاتِ الرضاع، وملاسة حلمة الأم محلمة العشيقة. حتّى عندما كنت بعيداً عنك- هل حقِاً أنت الآن

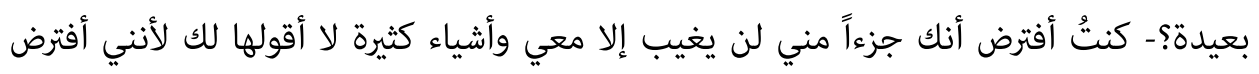
أنك تعرفينها، ثمّ إكتشف وقد غبتِ-- هل أنت حاضرة؟- أنني مُ أقل الحبَّ والهواجس والإستيهامات التي مل يفهمهما ويغفرها أحد سواك. أجلس الآن، هل تذكرين على حافة اللّحاف

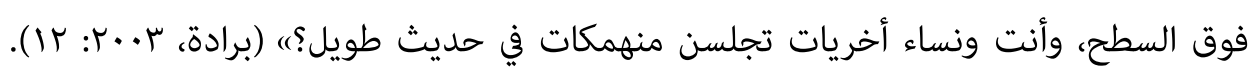
يعبر هذا النص عن آراء فرويد الذي يؤمن بأن؛ (مصدر الفن هو الخيال الذي يتمثل من خلاله الأبناء دور الآباء حيث يعتقدون أنهم يخلون عن دورهم في أن يصبحوا نوابا لآبائهم في الحياة

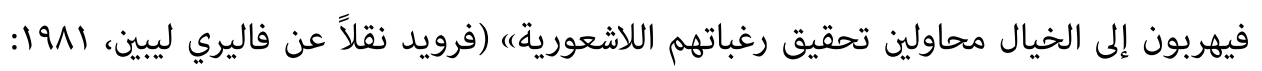
Vr VTr-VT). يحاول الهادي في هذه الرواية تعويض افتقار والده للمشاعر والعواطف وقضايا الحياة. الراوي لهذا الجزء من الرواية هو الهادي، الابن الأصغر للعائلة، الذي يهمس لنفسه ويتذكر

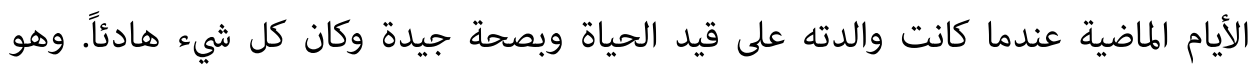
يطرح أسئلة لا يستطيع إلا التحليل النفسي الإجابة عنها. هذا يتماشى مع نظرية فرويد، ذلك ألى أن

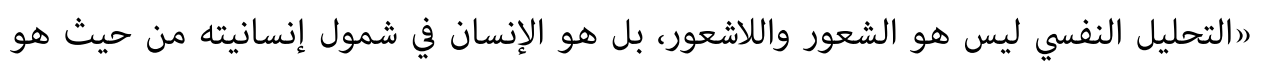


وحدة بيولوجية ولهذه الأسباب المجتمعة وجب الإهتمام بالتحليل النفسي، ووجب كذلك أن يتزود كل مفكر بأسئلته وبحقله المعرفي، إذ مها لانستطيع رده أن المرء قد يسأل في بعض إله المجالات أسئلة قد لايجيبه عنها إلا التحليل النفسي، (عبدالخالق، ل... ب: 00). خاصية أخرى للنوستالوجيا في الرواية هي حزن الهادي على فقدان خاله السيد الطيب، لأنه عاش في ذراعي خاله وهو طفل وذكرياته مليئة بالمشاعر الرائعة في ذلك الوقت؛ كما يري فرويد أن منبع العملية الإبداعية، هو اللاشعور، وأن معظم اللاشعور، مكتسب فردي، يرد صاحبه إلى زمن الطفولة. يتحدث الهادي لنفسه في هذه الرواية ويحكي عن آلامه لخاله سيد الطيب:

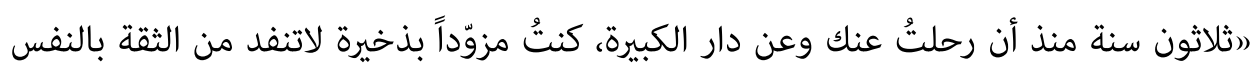
والجسارة وحبّ المغامرة، أبداً ملم تقمع رغائب طفولتي ولوكانت رعناء، وبذلك الحب الكثير أحسني قادراً على كل شئ. عام آخر استقبلني. تجارب معقدّة قطعت حبل السّرّة الرابط بيني وبين الكون الطفولة والأحلام. لكنني وأنا أعود إلى زيارتك. في كل مرّة تتبخّر السنوات الثلاثون وتتلاشي التصورات والأوهام وأعود طفلاً يحبو على مَدرج الصّبَوات وتطل النفس المكتفية بزمنها الأول الممتلئ. أجّدُ الباب دوما مفتوحا، ووجوه النساء والأطفال طافحة بالبشر والرضى. وأنت في صدر الغرفة بجلبابك وطوبوشك تنظر إلى الباحة أو تتحدث مع زوجتك أو مع أحد من سكان الدار. تعانقني فتنحّل العقد المتكوّمة في سريرتي، تتلاشي التساؤلات وهواجس الخوف) (برادة،

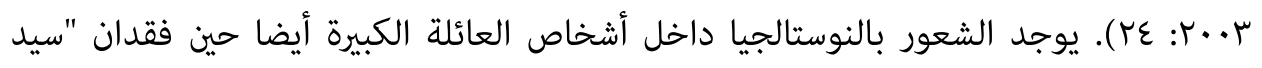
الطيب" أخ لأمّ الغالية. وحتى معظم الآلام في الأسرة مل يكن إلا بسبب افتقاد التاد السيد الطيب في عيشهم، وكان كالمصباح للعائلة وسبب فرحهم وضحكتهم قبل رحيله. النوستالوجيا هي آلة دفاع يستخدمها العقل لرفع المزاج وتحسين الحالة النفسية، لذا فإنها تكثر في حالات الملل أو الشعور بالوحدة خاصة عند كبار السن، أي عند شعور الإنسان بأن حياته فقدت قيمتها وأصبحت تتغير للأسوأ، فيقوم العقل باستدعاء ذكريات الماضي الطيبة بدفئها وعواطفها، فتعطيه تلك الذكريات الدفعة التي يحتاجها للتعامل مع التحديات الحالية؛ كما يقولون ذكريات الماضي سبب الطهأنينة ويهبط فيه الناس ليستعيدوا حياتهم ويشعروا بقيمتهم كما يوجد هذا داخل الهادي ويقول الراوي هكذا حوله: "إنه مايزال يحتفظ بالكثير ممّا لازمهُ منذ أن وعي بكورة الطفولة في أبعد تذكرات الارتداد إلى الماضي. وحين يفكر في كل ذلك، لايجد 
ما يستحصده سوى القول بأن الطفولة حاضرة فينا حضور الدم في الشرايين، وأن الغالب على الظن أن كل الناس-مثله فيما يخيل إليه- سيغمضون عيونهم عند الإحتضار، على لحظة أو له مشاهد من الطفولة المحفورة في الخلاياء والمسّام) (المصدر نفسه: وج). من أمثلة النوستالوجيا، الحنين واغتراب الهادي لطفولته وأيامها الجميلة بمدينة "فاس" وهو الآن رجع إلى مدينة الرباط عند عائلة أخته وزوجها وأمه وأخيه. وهو غير راضٍ عن العيش في الرباط تحت ضغط زورج زئه أخته، بل يريد الراحة والسلوان: (سيظل خياله مشدودا أمدا طويلاً إلى حركة الليل بفاس، وإلى

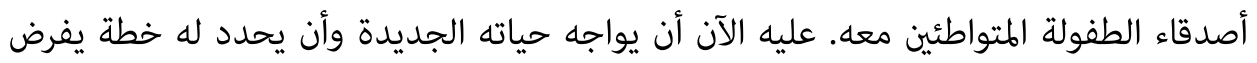
بها نفسه في هذا المحيط الذي يبدو غريبا عنه) (المصدر نفسه: مب). النوستالوجيا أو الحنين هو اهو حالة عاطفية نخلقها في مكان معين وفي أوقات وأماكن معينة. هناك مثل هذا الشغف والحنين إلى الماضي والطفولة في كلمات الطايع، هو يقول: (جزء من طفولتي في "فاس". مباريات كرة القدم صحبة الهادي في "الرباط". غاراتنا على الجنانات والعَرصات الواقعة آنذاك، في ديور الجامع وحي الليمون. إشتغالي بأوطيل "فاليدا" وارتداء البدلة والطربوش والإختباء تحت الكونتوار عندما ألمح واحدا من أصحابي مارّا بالقرب من مدخل الأوطيل)، (المصدر نفسه: 79).

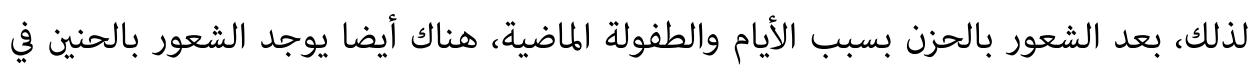
حياة عائلة أم غالية لأن أبناءها فقدوها ويواجهون هذا الحزن وهما دائما يذكرونها ويتحسرون بفقد أيامهم املاضية مع أمّهم ويؤدي إلى اليأس والكبت النفسي. هذا الشعور موجود في حياة أبناء الرواية في فقدان أمهم، علىالرغم من كل الشجاعة والمروئة في حياتهم كهذا اللاوعي حسب رأي فرويد؛ (الدوافع والرغبات المكبوتة التي يطلقها إسم الهو كما قلنا ويعرفه فرويد بأنه ذلك الأثر الذي يبقي في النفس من فترة الطفولة الطويلة التي يعيش فيها طفل معتمدا

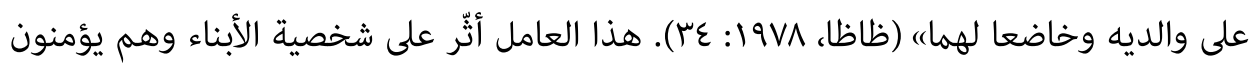
بالعجز والخوف من ظروفهم الصعبة دون أمّهم في المجتمع، لأنه تعتبر المرأة كنبض الحياة للأسرة والرّكيزة الأساسية، فالعلاقة بينها وبين الأسرة قائمة على المودّة والتفاهم. 
أن التصور اللاشعوري في نظرية التحليل النفسي هو عبارة عن تصورات لاشعورية مادية، فالتصور الشعوري في رأي فرويد: "يشمل في طياته تصورا ماديا، مصاغا كلاميا؛ أما التصور اللاشعوري فيتألف من تصور مادي صرف)، (ليبين، ا91 ا: 7ب)؛ ثمّ لايمننا أن نتعرف على هذا التصور المادي، إلا في شكل كلامي او لفظي، هي الفكرة المعروفة في التحليل النفسي باسم

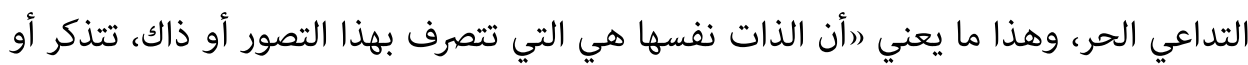
لا تتذكر هذا "المشهد" تحس أو لا تحس تلك المتعة وفي هذا المعني فإن الفصل (...) أو تقسيم في الذات الذي يحدثنا عنه التحليل النفسي دائما يجري فوق خلفية واحدة، خلفية ذات واحد)، (المصدر نفسه: ^). لقد تأسس منهج التداعيات الحرة على المعاني (المدلولات) المحددة لأية كلمة تلفظ بصورة عفوية ويصلح حسب رأي فرويد كمضمون مادي للعنصر النفسي اللاشعوري، (بنشعيب وآخرون، • • r: ع)، (افالنص الأدبي عند فرويد يشبه بالحلم يتضمن معنيين أحدهما ظاهر والآخر كامن ولايمكن أن تنفذ اليه إلا باستخدام طريقة التحليل النفسي وفق طريقة التداعي الحر وفهم الأحلام)، (المصدر نفسه: 1 1). اللاشعور في رأي فرويد عبارة عن مجموعة من العوامل والعمليات والدوافع المؤثرة في سلوك الفرد وفي تفكيره وعقله ومشاعره دون أن يكون عاما أو مدركا بها أو بكيفية حدوثها. هذا تأثير كبير على سلوكنا ومشاعرنا سواء في حياتنا السوية أو فيما نتعرض له من الاضطرابات والأمراض النفسية. والتداعي الحر سبب كل هذه العواطف والشعورات. من جهة أخرى , تيار الوعي يتيح لشخصيات الرواية التعبير عن نفسها، والكشف عن كل ما يدور بداخلها دون قيود ودون أهمية التسلسل المنطقي في أداء الموضوعات والمعلومات. وهو ما طبقه (افرويد نفسه على إحدى مريضاته وتدعى "إيمس فون" التي طلبت منه إثناء جلسات علاجها ألا يقاطعها بأسئلته ويدعها تسترسل في استرجاع ذكرياتها بالشكل الذي تريده) (عامود، إ..r: سجr). وقد اتكأ محمد برادة على مفهوم تيار الوعي في بناء روايته بشكل أساسي واستطاع من خلاله أن يسرد بزمن قصير حيوات الشخصيات التي امتدت منذ طفولة الهادي والطايع إلى بلوغهما وزواجهما وكهولتهما، ويقدم ماضي الشخصيات ولاسيما الهادي والطايع ويفسح لهما مجال التداعي الحر بر واسعا للتعبير عن أفكارهما وكشف معاناتهما ومشاعرهما تجاه العالم الروائي الذي يعيشان فيه. 
يمتاز البعد النفسي في الرواية بالقلق والإضطراب داخل الشخصيات وبسبب اختلاف الأسباب، تدفع الشخصيات إلى عدم الشعور بالطمأنينة. فقد كشف الهادي عن معاناته وكشف كابل عن ثقافته وشبكة علاقاته بالبنات والنساء طوال حياته كزوجة خاله , وهكذا يتكلم مع أمّه الراحلة: (أقرء عليك ما كتبته فتُلحِّين على لأُضيف: "نحن بخير ولايخصنا إلاّ النظر في وجهاكم

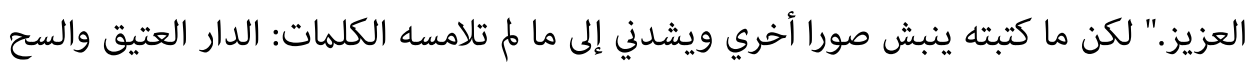
والدرب، وبنات الجيران، ولالة ربيعة ترقص دوما في مخيلتي بعينيها اللوزيتين الضاحكتين، طيفا ضعفا لزبيدة زوجة الرشيد المنقوشة بالرغائب مشتعلة في منطقة الشهوة والحب والتعلق

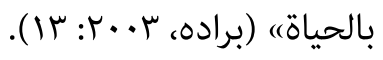
وقد كشف الطايع عن معاناته وشبكة اتصالاته التي جمعها في المجتمع الإسلامي خلال حياته، وعبر عن مشاعره حيال دراسته وعمله، كما كشف عن موقفه من بعض القضايا

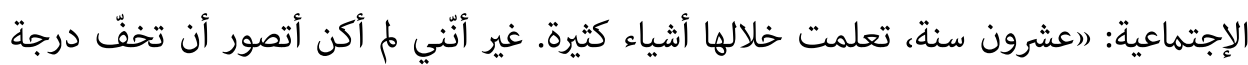
حرارتي ويهدأ الغليان إلى هذا الحد الذي أستطيع معه أن أتكلم عن سنوات "الهدم والبناء" بمثل هذا التباعد، بل والسخرية أحيانا. الجمر فيّ تحول إلى الرماد؟ بل إن رمادي احتضن جمراً آخر هو الذي يجعلني أنظر إلى تحولاتي بنوع من المرارة والعنف. أنا الآن مثابر على قرائة القرآن والدراسات المبشرة ببناء مجتمع الإسلامي تُبعث فيه حضارتنا التليدة الأصيلة. لست متعبا)، (المصدر نفسه: •V). إن الطايع يشبه "برثا بابنهايم"' في استعادته لذكريات العاطفية، ولاسيها الأحداث والمرارة في حياته ومشاعره تجاه هذه الأحداث: (أشعر بالنفور من فط عيش النخبة ومن تفشي العصرية وأدواتها. أجد نفسي أكثر في انكفائي وقرائة القرآن والصلاة مع الجماعة. عدة أشهر وأنا أحس الإنهزام والحرمان بسبب العجز عن متابعة الطريق التي نذرت نفسي لها. اكتشاف التناقضات حيث لاتتوقع ... جسدي لاأستطيع أن أتكلم عنه. في اللحظات الكآبة والشعور بالوحدة، أفكر كثيراً في الأم، وفي الموت، أقول إن على أن أهيئ نفسي للقاء الربّ) (المصدر نفسه: لَّ). لذا ترك الروائي شخصيته ليعيد ذكرياته وكل شيء بداخله بدون رابط زمني، فتداخلت المعلومات الققدمة والمونولوج الداخلي مع الشخصيات. وجعل الروائي روايته في مقاطع وقد طال بعضها إلى عدة صفحات، وفصل كل مقطع عن الآخر بإشارة استخدمها طوال روايته. وكل مقطع تلاه واحد من الشخصيات أحيانا عبر مونولوج داخلي- على سبيل المثال - تلاه 
مقطع الهادي و ذكرياته ومقطع بعدها تلاه الطايع عن مشاعره تجاه الحياة وهكذا تستمر الرواية وتتداخل ذكريات الهادي والطايع بين الجمل التحادثية. وتيار الوعي والتداعي الحر يتيح للشخصيات أن تنبش ما في نفوسها من مشاعر الظلم والقلق والحزن والإغتراب، وتكشف عن صراعاتها النفسية وتسرد شعورها للقارئ. كما برز لنا كل هذه الشعورات داخل الشخصيات من من مسات أمثال الطايع والهادي عبر تيار الوعي وتداعي الحر. r-ع. الحبّ

الحبّ في الاصطلاح النفسي هو؛ (الشعور بالتعلق بشخص أو بشئ ما، وهو ظاهرة نفيسة انفعالية ناجمة عن تأجج الإحساسات والمشاعر، ذاك الذي يطلق عليه اسم العاطفة) (سعيد،

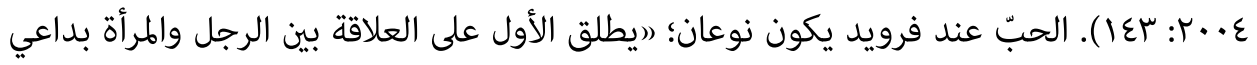
حاجاتهما الجنسية؛ أما الثاني فيطلق على العواطف الإيجابية التي تقوم ضمن نطاق الأسرة بين الأهل والأولاد، بين الإخوة والأخوات ويميل فرويد على تسمية النوع الثاني الحبّ المكفوف من

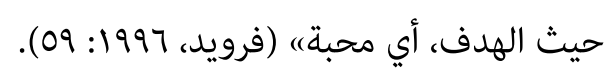

الحبّ الأول يعني بنوعيه علاقة الجنسية حسب تعبير فرويد، أخذ دورا مهما في تحريك أحداث الرواية، فالهادي والطايع هما الشخصيتان الرئيستان في الرواية ينطويان على كثير من لن الحبّ للمرأة؛ كما يوجد الحبّ للأنثى في حياة الهادي في طفولته عندما كان طفل وهو في حضن امرأة خاله "السيد الطيب"، هو يصف هكذا زوجة خاله: "جميلة كانت في بياضها الحليبي، بشعرها الفاحم وإبتسامتها الطَّيفية. نعومه متناهية. تمثال متناسق حتى كأنها ينتسب إلى عالم

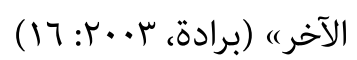
يتحدث الراوي أيضا عن الحب بين الهادي والفتيات هكذا: "(وهو ينمو، يبذر من حوله نكهة الحيوية والشيطنة وسط العائلات جُلُّل نصيبها من البنات. وستكون أولى الإثارات التميز لدى لدى لئي الهادي الطفل، إرسال شعر رأسه... وخلال الساعات لعب أطفال الدار وبناتها، يصبح الهادي

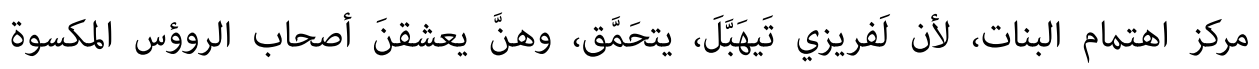
بالشعر، الحامة لأمارات العصر، وكثير ما يحاصرنَه في إحدى زوايا الغرفة، ليقبّلن قفاه ويعبثن بشعره. بداية مُغرية ومسلية. وسيظل، على امتداد الأيام، منجذبا على الحضور النّسوي الغنّي 
بِالسحر والفتون) (المصدر نفسه: وץ-·ץ). هذه اللحظات سبب بداية الحب داخل الهادي ويبدو الشعور بالحب في هذا النص ويرمز إلى الرغبة والتمني وهذا الحب يدل على الإحساس والشعور الداخلي عبّر به الشخص عن رغبته بمحبوبته.

هناك حب في حياة الطايع وهو يتحدث إلى نفسه في مونولوج ويتكلم عن حبه للفتيات الهجاور والفتاة اليهودية: (ما جدوي أن أحكي عن حبي الطبكر لابنة الجيران عندما جئنا إلى الرباط؟ وعن تنقلي بين الدكاكين والكهن لأعول أمي وأخي ثم لأسدد نفقات تعليمة مكتفيا أنا بالشهادة الإبتدائية؟ ما جدوي أن أحكي عن تلك الفتاة اليهودية التي تعلقتُ بها عندما كنتُ أشرف على دار الخياطات التي كلفني بها تاجر مشهور في ذلك الوقت؟)، (المصدر نفسه: 79) فالحبّ الثاني الذي يطلق على العواطف الإيجابية بين الأسرة والأهل والأولاد، هي المودة والإخلاص الذي ترفض الإنفصال، وهو جميل بطيفه وذكرياته، والوفاء تكون سمة بارزة لهذا النوع من العلاقة كما توجد هذه العلاقة بين اللآلة الغالية وأخيها. هي تحب أخاها وكان أخوها أيضا يحبها حتى هذه العلاقة تصير سبب غضب سائر أشخاص هذه العائلة الكبيرة من أمثال النساء كما تقلنّ النساء الراويات: (ما يغيظنا أحيانا، هو حبّها المفرط لأخيها الأكبر الطيب. تلهج بذكره، وتتحمل كل الإهانات من زوجته، لاتسأله حسابا عن كرائاتها، تأخذ ما يملُّه لها. تحدثه باحترام ولاتحب أن يتحدث عنه أحد بسوء... هو أيضا يحبها. تَعاطُفُهُما يظلل الدار، ويوشج الروابط بين سكانها. الألفة والمودة تَزرع في الأفئدة عندما نراها مشخصةً أمامناه، (المصدر نفسه:

هناك صورة أخرى للشعور بالحب وهذا هو ما يحدث داخل الهادي بنسبة لأخته؛ فهذه

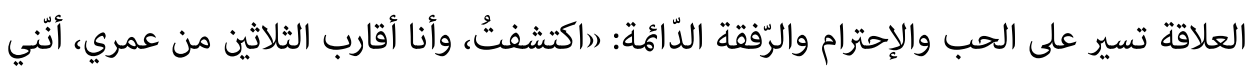
أكنّ حبّا خاصا لأختي لالة نجية. ودّ عجيب، عارم، يحاصرني، يحملني إلى زيارتها بغير سبب. أتحدث معها في شؤون العابرة ونسترجع سوية ذكريات من طفولتنا، (المصدر نفسه: זٓ-س7). وفي النهاية يعلن الهادي حبه لأخته بأنه يحبها أكثر من زوجها وأولادها: (بعد الفترة، ونحن نحتسي الشاي، قلتُ لها هل تعلمين بأنّني أحبك أكثر مما يحبّك أولادك وربما أكثر مما يحبك سي إبراهيم نفسه؟) (المصدر نفسه: 70). يبقي هذا الحب على الإخلاص والصداقة ومن هذا القول 
نفهم بأنَّ الهادي مازال يحتفظ بعلاقته ومودته لأخته كما في السّابق وهذا الحب ليس في قلبه

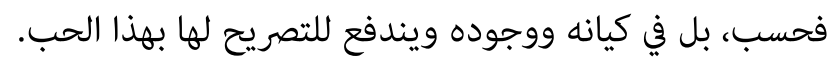

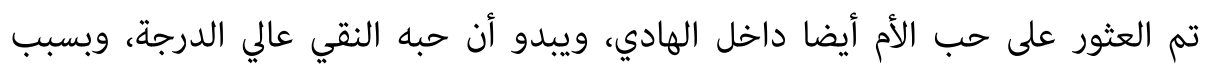

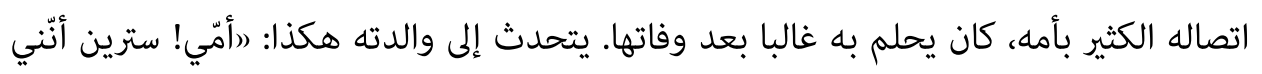

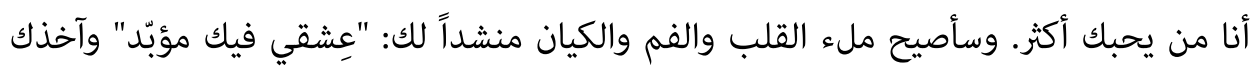

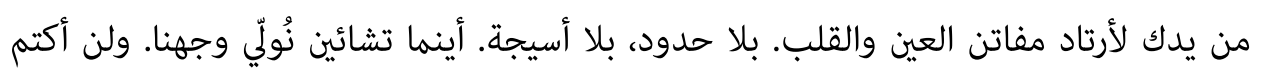

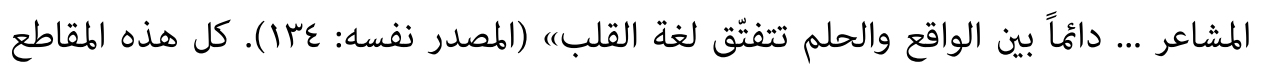

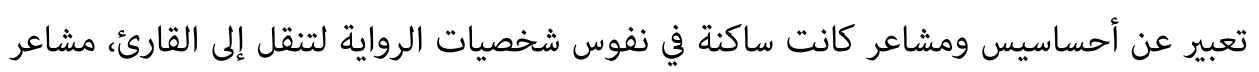

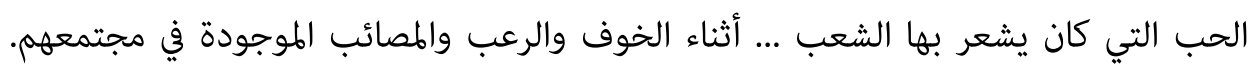

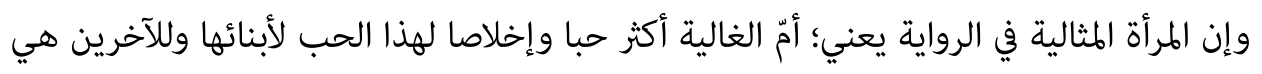

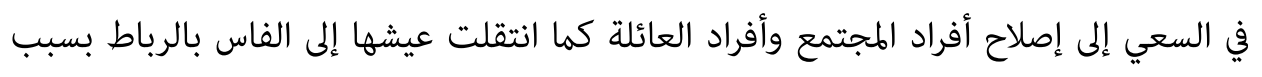
مساعدة ابنتها في تربية أولادها. لذلك حبها لبنتها هو الذي دفعها إلى العيش بالرادياط.

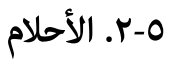

الأحلام من أهم الموضوعات التي درسها فرويد وتوجها بصدور كتابة المشهور تفسير الأحلام

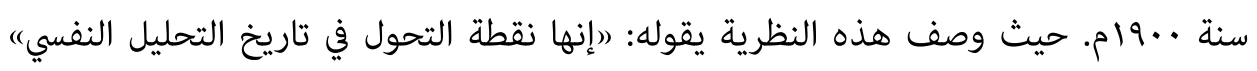

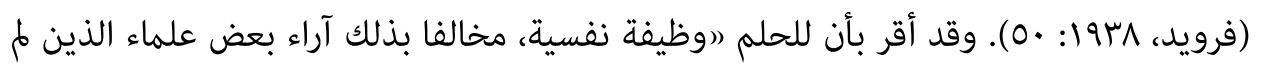

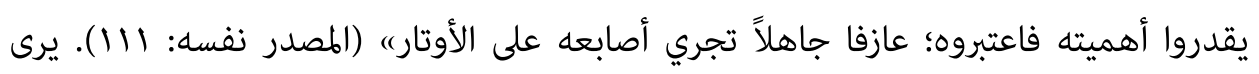

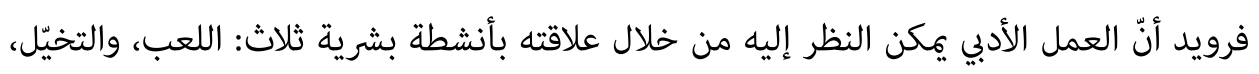

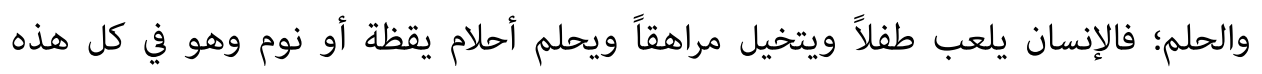

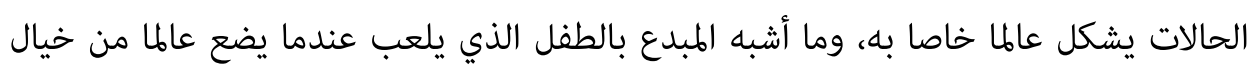

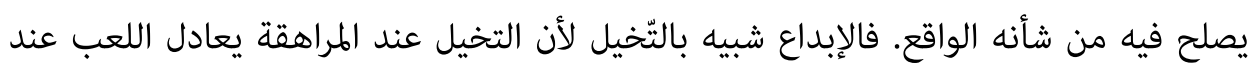

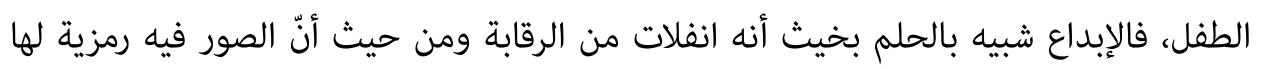
باطن وظاهر. 
كانت الأحلام محل اهتمام كثير من الناس وخاصة في زماننا هذا؛ حيث الظروف المضطربة عائليا، واجتماعيا، واقتصاديا، وسياسيا، والناس يكتمون ويتعلمون أن يخفوا بأنفسهم ولايظهروا انفعالات وتطلعاتهم وطموحاتهم فتكثر الأحلام. تعد الأحلام أقوى دليل على وجود اللاوعي وثرائه ويعرّف فرويد الحلم بأنّه: (تحقيق مقنع لرغبة مقموعة أو مكبوتة) (حيدوش، و +.ب: 1) وهو يقول حول الأحلام: (هي وسيلة تلجأ إليها النفس لإشباع رغباتها ودوافعها المكبوتة خاص التي يكون إشباعها صعب في الواقع، وفي الأحلام يرى الفرد دوافعه قد تحققت في الصورة حدثت أو موقف، فالأحلام إذن تبقي من أهمّ الوسائل الكاشفة عن مكونات الأنا وأعماق النفس، وأبعاد الشخصيات) (الحنفي، 1941 (9). وهي وسيلة تتحقق فيها رغبة بالنوم وفي نفس الوقت تسمح بأشباع الرغبات المكبوتة التي تظهر تفاصيلها في الأحلام وتحقيق لرغبة مكبوتة في شعور الإنسان. الأحلام نوعان؛ الحلم الذي يراه الشخص في النوم، والحلم الذي يطلق عليه أحلام اليقظة. وقد برزت هذه الأحلام في الرواية للقارئ من خلال حواراته الشخصيات الداخلية والظلم والكآبة التي برز تأثيرها في ظهور النوع الثاني. يوجد نوع من الحلم في كلام الهادي مع أخته بطريقة حوار داخلي، لأنه أشعر بالبعد عن أخته ويقول كل مرة التي رآها، ليس شئ سوى أحلام اليقظة: (اعناقيد ورد، أم أكاليل دم، أو أعراس حلم، لكنه الفرح، الفرح، تقولين، يستغني عن كل عقل ... أتذكرك و أحاول أن أقنع نفسي بأن صورتك في المقهى مل تكن سوى كابوس عابر اختلط

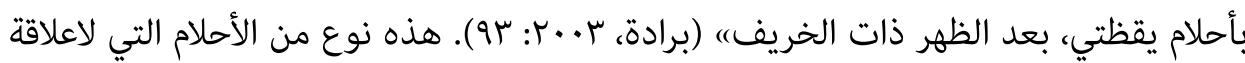
لها بالنوم وهي أحلام اليقظة التي تعد أهم مسببات تشتت انتباه الإنسان؛ يعني ينغمس الشخص بأحلامه خلال يقظته وتسبب الشرود وعدم الانتباه ويحاول الإنسان أن يعيد إلى خياله

صور الذكريات التي قد مرّت به من قبل وقد تراوده أفكار ذات صلة باللحظة التي يعيشها. لالةنجية ترى شدة تأثير النوع الأول من الأحلام في عيشها، كأنّ كل حياتها أحلام والذكريات والمشاعر هي تقول هكذا مع أخيها هادي عن امتزاج العيش بالأحلام: (العلك لاتستطيع أن تدرك تاما حالة من يعيش حياته من خلال سلطة قبلية تصادر أحلامه وأهوائه، وتحرمه من أن يكشف، بجسده، ومشاعره، أوهام الفعل الحر والإنتشاء بالتجربة)، (المصدر نفسه: 90). وكأن كل العيش في التناقض مع الأحلام والواقع أم شئ يشبه ضده: (أبيض- أسود، خريف- شتاء، 
حزن- فرح، حب- كراهية؛ بينهما تتناسج العواطف والأفكار والأحلام، من جدليتهما تنبثق مطمح الاستمزاج والهجانة المخصبة، وتنبجس الشهوة يافعةً منفلتة من صدإ الرتابة والإعتياده، ينهاه (المصدر نفسه: rع).كلها أفكار وذكريات يمكن أن ينتج عنها القلق والخوف في مجال الشعور الشخصي لدى الشخصيات والإبتعاد عن الواقع والهروب من الحصار المفروض في العيش

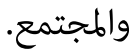

ونوع من الأحلام يوجد في نوم الشخصيات، على عكس أحلام اليقظة. هذه الأحلام يمكن تفسيرها بتجلي الأنا الأعلى فيها. وقد تكرر هذا النوع من الأحلام غير مرّة، مثل ما تحكي لالة نجية من منامتها التي تزوره حول أمّها لإخوانها، واللون الأبيض اللصيق بأمّها، قاسما مشتركا بين هندين هذه الأحلام ويكننا تفسير هذا النوع من الأحلام بالاستعانة بالنهج الإسلامي: (ريحاسبني الله، شفتُ أمي لالة الغالية وهي لابسة شالها الأبيض)هي تحكي منامتها وأنا أري: رأيتُ أمي، رأيتُ هُهِ أمي. كانت متلألئة، ممتلئة بحقيقتها، واثقة في اطمئنان، تبتسم في رضي صوب تلكي لكابل الوجوها الفتية والجثث المستيقظة من مراقدها...) (المصدر نفسه: بَr(). هذا النص هو تجسيد للكآبة والحزن والصراع الذي يوجد داخل لالة نجية منذ أن تفقد أمها. وسبب هذا الحلم هو الواقع مراتع وهمومه وما يحتويه من ظروف تحيط بالشخصية.

مع البحث في المنهج النفسي في رواية "لعبة النسيان" شعرنا كل هواجس واضطرابات الشخصيات حول الحياة وعرفنا أفكارهم ورأينا في هذه الرواية، الحالة النفسية التي تعيشها الشخصيات الرئيسة والتي تظهر لنا أن الأدب دائم؟ الإقتران بالتحليل النفسي، فالكاتب لابدَّ يستنسخ روايته من الواقع، لذلك يصوّر لنا محمد برادة في هذه الرواية، حياة مجتمعه المغربية المعاصرة في أواخر فترة الإستعمار ويبينَ لنا تلك المعاناة النفسية التي يمر بها البطل والشخصيات الثانوية. لذلك يوجد الإهتمام بالجانب النفسي في الرواية من خلال تصوير مشاعر الشخصيات 
وعواطفهم وسلوكهم مع القضايا المحيطة بها. يعد الصراع النفسي، الشعور بالنقص، تيار الوعي

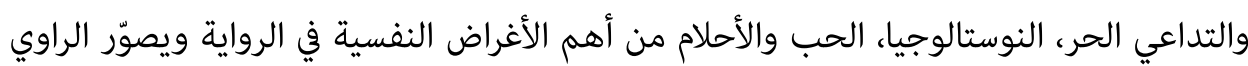
حياة شخصيات مجتمعه من خلال هذه الأغراض. توجد داخل الشخصيات العقد والأمراض

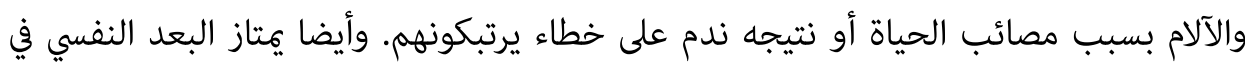
هذه الرواية بالتوتر والقلق والإضطراب الذي يبدو قاسما مشتركا داخل كل الشخصيات رغم اختلاف الأسباب وهذا يسبب أن تدفع الشخصيات إلى عدم الشعور بالطمأنينة. والإحباط إلى

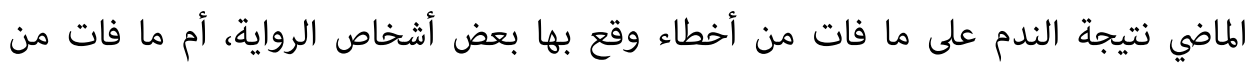
ذكريات الجميلة والطفولة وحياتها مملوء بالطمأنينة. فشخصيات الرواية متأزمة تعاني من واقع المرير، يبحثون عن حياة كريمة ولايجدون إلا البؤس والصراع النفسي، يحلمون بقصة الحب والعيش الجميل وبأمنيات البسيطة فلاتدركها إلا مشاعر الحرمان والعوز. ويجعلهم يشعر بأن

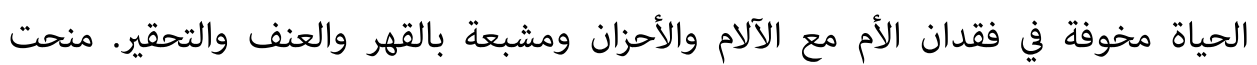
الأحلام أيضا دورا ايجابيا في إضائة البواطن الداخلية للشخصيات وتعريتها للقارئ والكشف عن واهن مشاعره وأحاسيسه وأفكاره والغربة التي يعانيها الشخصيات لفقدان أمّهم. ويبدو الاهتمام بالجانب النفسي في الرواية من خلال تصوير مشاعر الشخصيات وعواطفها وسلوكها، وطباعها ومواقفها من القضايا المحيطة بها. كما يبدو من العقد والأمراض النفسية التي المت بها بسبب مصاعب واجهتها في الحياة، أو نتيجة ندمها على أخطاء ارتكبتها، أو نتيجة كونها ضحية ممارسات ظالمة مارستها شخصيات أخرى بحقها.

ابن قتيبة (د.ت)، الشعر والشعراء، تحقيق وشرح أحمد محمد شاكر، القاهرة: دارالمعارف. برادة، محمد (س. . (ץ)، لعبة النسيان، الرباط: دارالأمان.

بن شعيب، خالد ومحمد بشير بويجرة (•(ب)، (اليليات إمرأة آرق في ضوء التحليل النفسي"، مذكرة مقدمة لنيل شهادة ماستر، الجمهورية الجزائرية، كلية الآداب؛ جامعة وهران، قسم اللغة العربية وآدابها. 
• ترينلج، ليونيل (19V0)، فرويد والأدب؛ ترجمة حسام الخطيب، دمشق: مطبعة بطريق.

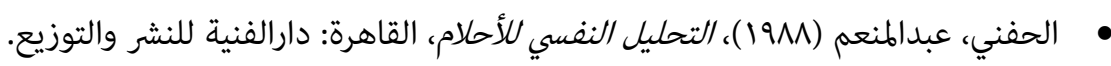

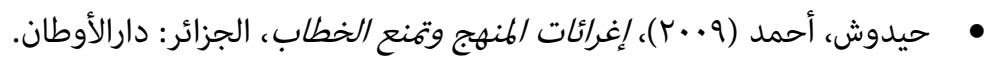

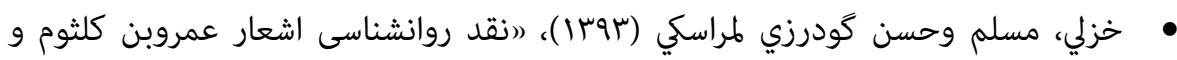
عنترة بن شداده،، فصلنامه لسان مبين، سال ششم، شماره IV، صص rا-19.

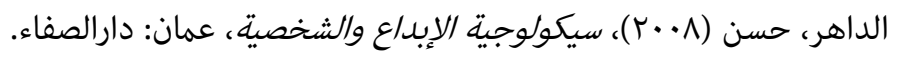

ذهني، محمود (د.ت)، تذوّق الأدب؛ طرقه ووسائله، القاهرة: مكتبة الأنجلو المصرية.

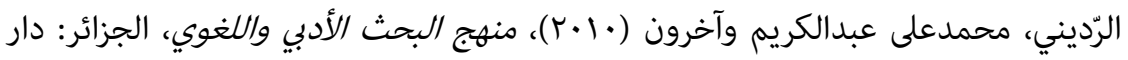

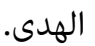
• ساحي، زوبة وصبرينة أومخلوف (عا.ب)، "المنهج النفسي عند أحمد حيدوش من خلال

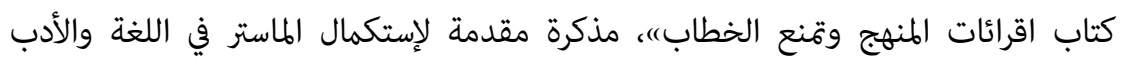
العربي، أدب الجزايري، جامعة بجاية.

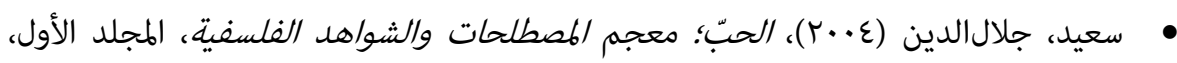
تونس: دار الجنوب. ظاظا، رضوان (19VN)، مدخل إلى مناهج النقد الأدبي، ط r، الكويت: دارالعربية للنشر

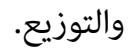

عامود، بدرالدين (1 · ( )، علم النفس في القرن العشرين، دمشق: اتحاد الكتاب العرب. عباس، فيصل (1997)، التّحليل النّفسي والإتجاهات الفرويدية، (أغاربة العيادية، بيروت: دارالفكر العربي.

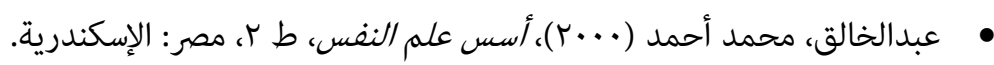

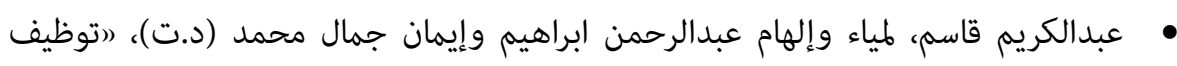
النوستالجيا في بناء الرسالة الإعلانية؛ دراسة على الإعلان التلفزيوني بهصر)، مجلة العمارة

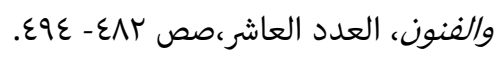
عكاشة، شايف (1910)، اتجّاهات النّقد (لعاصر في مصر، الجزائر: ديوان المطبوعات 


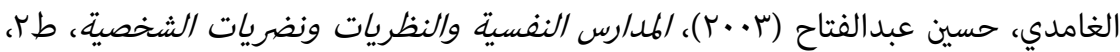
الإسكندرية: دارالوفاء.

فرويد، سيغموند (بسوا()، محاضرات تمهيدية جديدة في علم النفسي، ترجمة: أحمد عزت راجح، القاهرة: مكتبة الأنجلو المصرية.

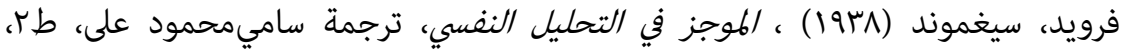

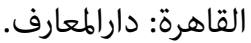

فرويد، سيغموند (ع\11)، الحلم وتأويله، ترجمة جورج طرابيشي، طب، بيروت-لبنان: دارالطليعة.

فرويد، سيغموند (19M1)، الأنا والهو، ترجمة محمدعثمان نجاتي، القاهرة: دارالشرق

فرويد، سيغموند (1997)، قلق في الحضارة، ترجمة جورج طرابيشي، بيروت: دارالطليعة.

لابلانش، جان وبوانتالس (r..r)، معجم مصطلحات التحليل النفسي، ترجمة مصطفي

حجازي، بيروت: مؤسسة الجامعية للنشر.

• ليبين، فاليري (1911)، منهب التحليل النفسي والفلسفة الفرويدية الجديدة، بيروت:

دارالفارابي.

مجموعة من المؤلفين (ع991)، مقدمة في (6ناهج النقدية للتحليل الأدبي، ترجمة وائل بركات

$$
\text { وغسان السيّد، باريس: مطبعة زيد بن ثابت. }
$$

مجيدي، حسن و محمد غفوريفر وجواد عابدي (عqسا)), "بررسى و تحليل شخصيت ابن

رومي بر اساس نظرية عقدة حقارت آدلر)، فصلنامه لسان مبين، سال ششم، شماره •r،

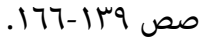

الوافي، عبدالرحمن (1) (r)، ملخل في علم النفس، طه، الجزائر: هومة للطباع والنشر.

\section{References}

- Ibn Qutayba (n.d), Poetry and Poets, verified and explained by Ahmad Muhammad Shaker, Cairo: Dar Al-Maarif.

- Barada, Muhammad (2003), The Game of Forgetfulness, Rabat: Dar Al-Aman.

- Ben Shoaib, Khaled and Mohamed Bashir Bouijra (2010), "The Nights of an Insomniac Woman in the Light of Psychoanalysis", a note submitted for obtaining a master's degree, Republic of Algeria, Faculty of Arts; Oran University, Department of Arabic Language and Literature. 
- Trinnellj, Lionel (1975), Freud and Literature; Translated by Hussam AlKhatib, Damascus: Penguin Press.

- Al-Hafni, Abdel-Moneim (1988), Psychoanalysis of Dreams, Cairo: Dar AlFaniyah for Publishing and Distribution.

- Haidouch, Ahmed (2009), The Temptations of the Curriculum and the Prevention of Discourse, Algeria: Dar Al-Awtan.

- Khazli, Muslim and Hassan Godarzi Lamraski (1393), "Criticism of Rawanashnasi Poetry of Amr Ibn Kulthum and Antarah Ibn Shaddad", Vsnama $\neg$ Lisan Mubin, Sal Shashem, Shamarah $\neg$ 17, pp. 62-89.

- Al-Daher, Hassan (2008), The Psychology of Creativity and Personality, Amman: Dar Al-Safaa.

- Zehni, Mahmood (n.d), A taste of literature; His Ways and Means, Cairo: The Anglo-Egyptian Library.

- Al-Radini, Mohamed Ali Abdelkarim and others (2010), Literary and Linguistic Research Methodology, Algeria: Dar Al-Huda.

- Sahi, Zouba and Sabrina Umkhlouf (2014), "The Psychological Approach of Ahmed Haidouch through the book Readings of the Curriculum and the Prevention of Discourse", a memorandum submitted to complete the master's degree in Arabic language and literature, Algerian literature, Bejaia University.

- Said, Jalaluddin (2004), Love; Dictionary of Philosophical Terms and Evidence, Volume One, Tunis: Dar Al-Janoub.

- Zaza, Radwan (1978), Introduction to Literary Criticism Curricula, 2nd Edition, Kuwait: Dar Al-Arabiya for Publishing and Distribution.

- Amoud, Badreddine (2001), Psychology in the Twentieth Century, Damascus: The Arab Writers Union.

- Abbas, Faisal (1996), Psychological Analysis and Freudian Attitudes, Clinical Maghrebians, Beirut: Dar Al-Fikr Al-Arabi.

- Abdel-Khaleq, Mohamed Ahmed (2000), Foundations of Psychology, 2nd Edition, Egypt: Alexandria.

- Abdul Karim Qassem, Lamia and Ilham Abdul Rahman Ibrahim and Iman Jamal Muhammad (n.d), "Using Nostalgia in Building the Advertising Message; A study on television advertising in Egypt," Architecture and Arts Journal, Issue Ten, pp. 482-494.

- Okasha, Shaif (1985), Trends of Contemporary Criticism in Egypt, Algeria: Diwan of University Publications.

- Al-Ghamdi, Hussein Abdel-Fattah (2003), Psychological Schools, Theories, and Personal Theories, 2nd Edition, Alexandria: Dar Al-Wafa.

- Freud, Sigmund (1932), New Introductory Lectures on Psychology, translated by: Ahmed Ezzat Rageh, Cairo: Anglo-Egyptian Library.

- Freud, Sigmund (1938), The Summary in Psychoanalysis, translated by SamiMahmoud Ali, 2nd Edition, Cairo: Dar Al-Maarif.

- Freud, Sigmund (1984), The Dream and its Interpretation, Translated by George Tarabishi, 2nd Edition, Beirut - Lebanon: Dar Al-Tali'a.

- Freud, Sigmund (1988), The Ego and the Id, translated by Muhammad Othman Nagati, Cairo: Dar Al-Sharq 
- Freud, Sigmund (1996), Anxiety in Civilization, translated by George Tarabishi, Beirut: Dar Al-Tali`ah.

- Lablanche, Jean and Pointalis (2002), A Dictionary of Psychoanalytic Terms, translated by Mustafa Hijazi, Beirut: Jamia Institute for Publishing.

- Lipin, Valerie (1981), Psychoanalysis and the New Freudian Philosophy, Beirut: Dar Al-Farabi.

- A Group of Authors (1994), Introduction to Critical Approaches to Literary Analysis, translated by Wael Barakat and Ghassan Al-Sayed, Paris: Zaid Bin Thabet Press.

- Majidi, Hassan, Muhammad Ghafuri-Far and Jawad Abedi (1394), "Barsi and the analysis of Ibn Rumi's personality based on the theory of the Haqarat Adler complex", Vsnama $\neg$ Lisan Mubin, Sal Shashem, Shamara $\neg 20$, pp. 139-166.

- Al-Wafi, Abdel-Rahman (2011), Introduction to Psychology, 5th Edition, Algeria: Homa for printing and publishing. 


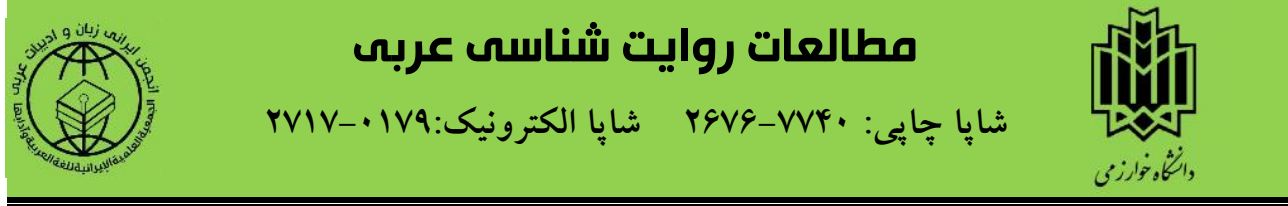

نقد روانشناختى رمان "لعبدُ النسيان " اثر محمد براده از ديدگاه فرويد gh.karimifard@scu.ac.ir

رايانامه: غلامرضا كريمىفرد

دانشيار زبان و ادبيات عربى دانشعاه شهيد جمران اهواز. اهواز، ايران (نويسنده مسئول) parvinkhalili93@gmail.com رايانامه:

يروين خليلى

دانشجوى دكترى زبان و ادبيات عربى دانشخاه شهيد جمران اهواز. اهواز، ايران masoudbavanpouri@yahoo.com رايانامه:

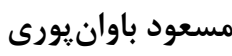

$$
\text { دكترى زبان و ادبيات عربى، دانشعاه شهيد مدنى آذربايجان، تبريز، ايران. }
$$

جكيده ج امروزه روانشناسى جزئى جدايىنايذير از ادبيات شده است و براى فهم صحيح يك متن ادبى ضرورى است در

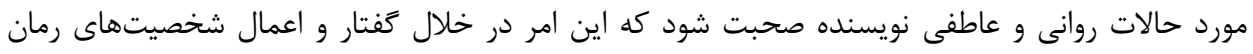

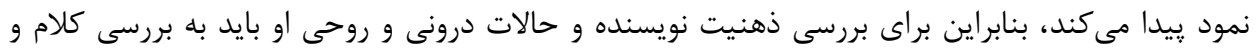

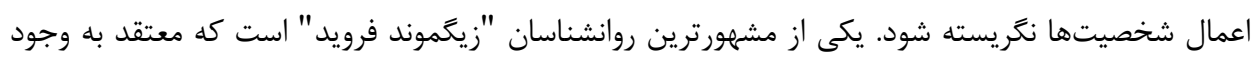

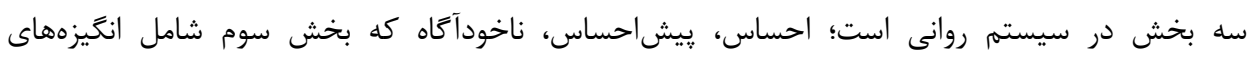

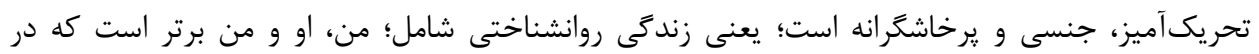

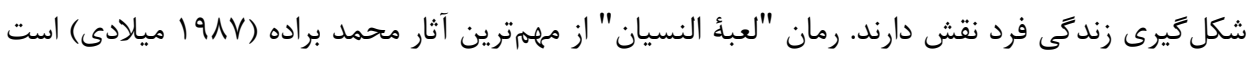

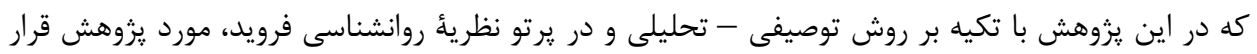

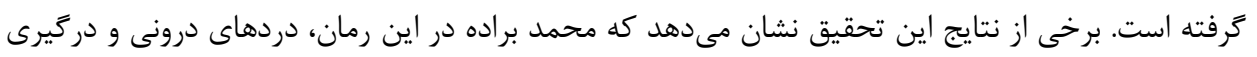

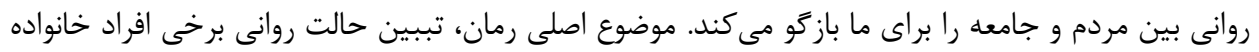

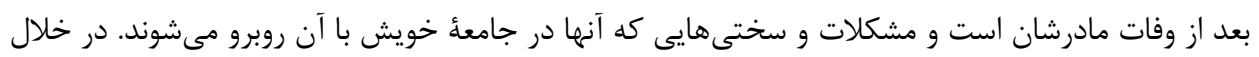

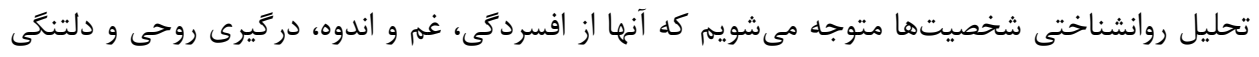

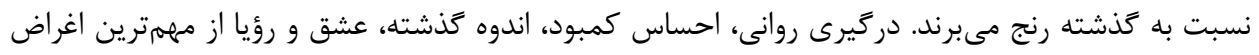

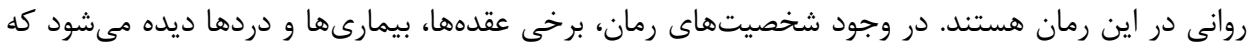

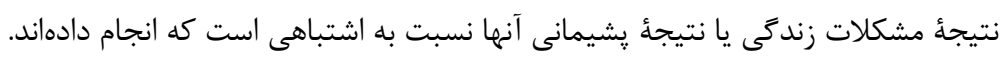
وازگًان كليدى: رمان، نقد روانشناختى، فرويد، محمد براده، لعبهُ النسيان، روايتشناسى عربى.

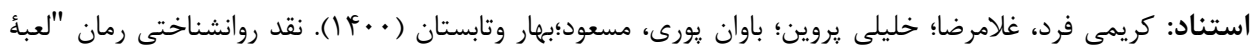

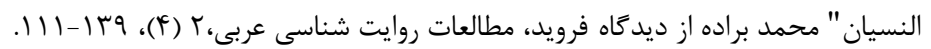




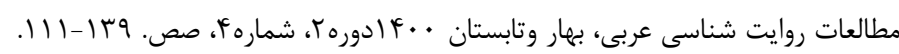

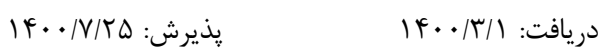

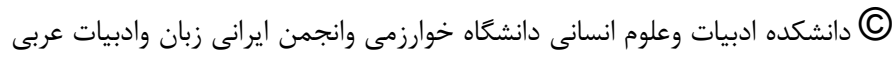

